\title{
Noble Gases Preserve History of Retentive Continental Crust in the Bravo Dome Natural $\mathrm{CO}_{2}$ Field, New Mexico
}

Kiran J. Sathaye $^{a *}$, Andrew J. Smye ${ }^{a, 1}$, Jacob S. Jordan ${ }^{a}$, Marc A. Hesse $^{a}$

${ }^{a}$ Department of Geological Sciences, University of Texas at Austin, USA

1 Presently at: Department of Earth Sciences, University of Oxford, United Kingdom *Corresponding Author: kiransathaye@utexas.edu

\begin{abstract}
Budgets of ${ }^{4} \mathrm{He}$ and ${ }^{40} \mathrm{Ar}$ provide constraints on the chemical evolution of the solid Earth and atmosphere. Although continental crust accounts for the majority of ${ }^{4} \mathrm{He}$ and ${ }^{40} \mathrm{Ar}$ degassed from the Earth, degassing mechanisms are subject to scholarly debate. Here we provide a constraint on crustal degassing by comparing the noble gases accumulated in the Bravo Dome natural $\mathrm{CO}_{2}$ reservoir, New Mexico USA, with the radiogenic production in the underlying crust. A detailed geological model of the reservoir is used to provide absolute abundances and geostatistical uncertainty of ${ }^{4} \mathrm{He},{ }^{40} \mathrm{Ar},{ }^{21} \mathrm{Ne},{ }^{20} \mathrm{Ne}$, ${ }^{36} \mathrm{Ar}$, and ${ }^{84} \mathrm{Kr}$. The present-day production rate of crustal radiogenic ${ }^{4} \mathrm{He}$ and ${ }^{40} \mathrm{Ar}$, henceforth referred to as ${ }^{4} \mathrm{He}^{*}$ and ${ }^{40} \mathrm{Ar}^{*}$, is estimated using the basement composition, surface and mantle heat flow, and seismic estimates of crustal density. After subtracting mantle and atmospheric contributions, the reservoir contains less than $0.02 \%$ of the of the radiogenic production in the underlying crust. This shows unequivocally that radiogenic noble gases are effectively retained in cratonic continental crust over millennial timescales.
\end{abstract}


This also requires that approximately $1.5 \mathrm{Gt}$ of mantle derived $\mathrm{CO}_{2}$ migrated through the crust without mobilizing the crustally accumulated gases. This observation suggests transport along a localized fracture network. Therefore, the retention of noble gases in stable crystalline continental crust allows shallow accumulations of radiogenic gases to record tectonic history. At Bravo Dome, the crustal ${ }^{4} \mathrm{He}^{*} /{ }^{40} \mathrm{Ar}$ ratio is one fifth of the expected crustal production ratio, recording the preferential release of ${ }^{4} \mathrm{He}$ during the Ancestral Rocky Mountain orogeny, 300 Ma.

\section{Introduction}

The abundances of radiogenic noble gases in the Earth's atmosphere have 3 long been used to constrain the structure and composition of the Earth's 4 mantle $[1,2,3]$. Roughly $70 \%$ of the ${ }^{4} \mathrm{He}$ and ${ }^{40} \mathrm{Ar}$ degassed from the bulk 5 silicate Earth derives from the continental crust $[4,5]$. A clear understanding 6 of the flux of noble gases from the continental crust is hampered by spatial 7 and temporal variability of flux measurements at the Earth's surface. We overcome this limitation by calculating absolute noble gas abundances in the 9 Bravo Dome natural $\mathrm{CO}_{2}$ reservoir, which represent time-integrated fluxes

abundances are compared with radiogenic production of ${ }^{4} \mathrm{He}$ and ${ }^{40} \mathrm{Ar}$ in the underlying crust, based on a seismic density profile and heat flux in the region.

\subsection{Previous Work on Crustal Degassing}

Previous estimates of average crustal degassing fluxes have relied on ${ }^{4} \mathrm{He}$ and ${ }^{40} \mathrm{Ar}$ accumulation in large regional aquifers $[10,11,12,13,14,15]$. How- 


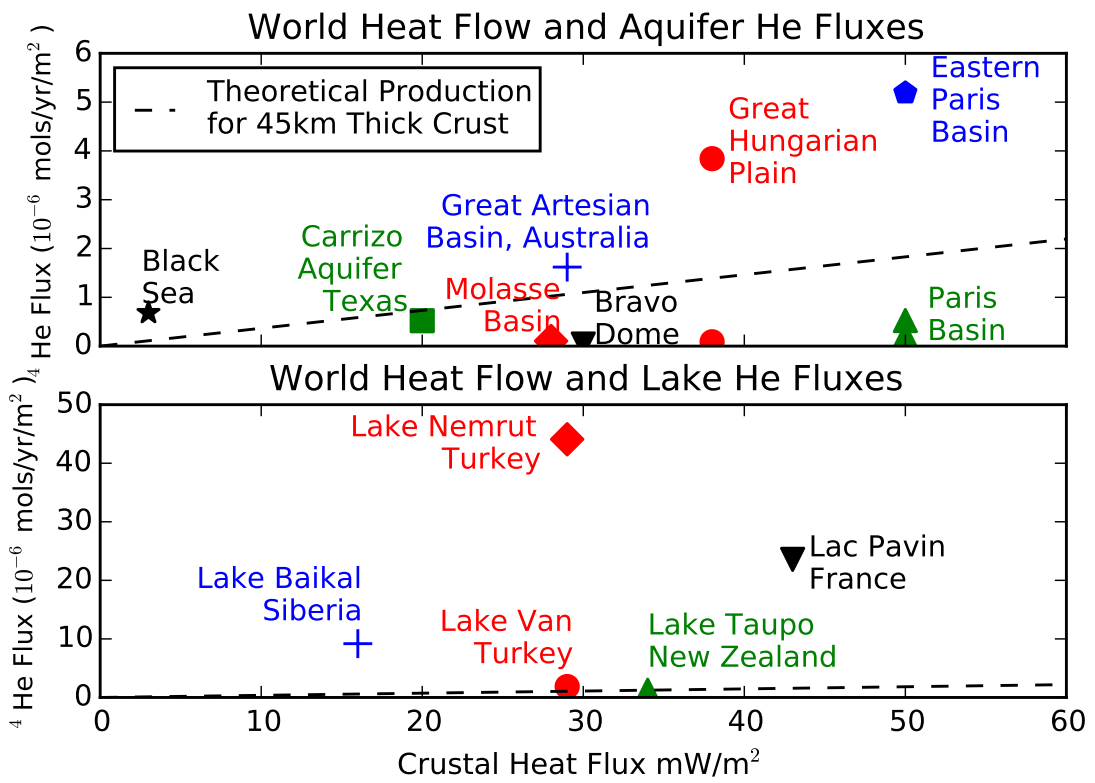

Figure 1: Previously estimated helium fluxes and corresponding radiogenic heat production in the crust $[6,7,8,9]$. Measurements with close proximity have varying ${ }^{4} \mathrm{He}$ fluxes, suggesting sporadic and advective ${ }^{4} \mathrm{He}$ degassing. 
ever, ${ }^{4} \mathrm{He}$ residence time estimates rely on knowledge of the ${ }^{4} \mathrm{He}$ source and sink terms $[10,16]$. Figure 1 shows that estimates of degassing fluxes based on regional aquifers vary between 3\% and 300\% of the expected crustal production. This variation may reflect heterogeneity of the degassing fluxes or the inherent difficulty of understanding dynamic aquifer systems [6]. Similarly, the ${ }^{4} \mathrm{He}$ flux in lakes has been measured up to three orders of magnitude greater than expected crustal production $[6,17]$. A review of these studies shows that estimates of the ${ }^{4} \mathrm{He}$ degassing flux decrease with increasing spatial and temporal scales [6].

Crustal degassing can occur by diffusion along mineral grain boundaries or by advective transport in a migrating fluid phase. Transient variations in degassing fluxes have been observed in several field areas [18, 19]. Thus, the large spatial and temporal ${ }^{4} \mathrm{He}$ and ${ }^{40} \mathrm{Ar}$ flux averages recorded by the Bravo Dome gas field represent a significant advantage over extrapolation of degassing fluxes calculated from discrete points in space and time [19]. For crustal degassing studies, the Bravo Dome gas field is analogous to a large subsurface lake, acting as a volume of fluid accumulating flux and partitioning volatile dissolved gases from below (Figure 2). In fact, the Bravo Dome gas offers two advantanges over lake studies: it scavenges dissolved gases from the underlying brine through phase equilibrium, and remains isolated from the atmosphere due to the impervious evaporite cap rock [20].

\subsection{Bravo Dome Introduction}

Bravo Dome is a large natural gas reservoir in northeastern New Mexico (Figure 3A). The reservoir covers an area of $3600 \mathrm{~km}^{2}$ and contained $1.3 \mathrm{Gt}$ of nearly pure $\mathrm{CO}_{2}$ before commercial extraction in 1981 [20, 21]. The gas is of 

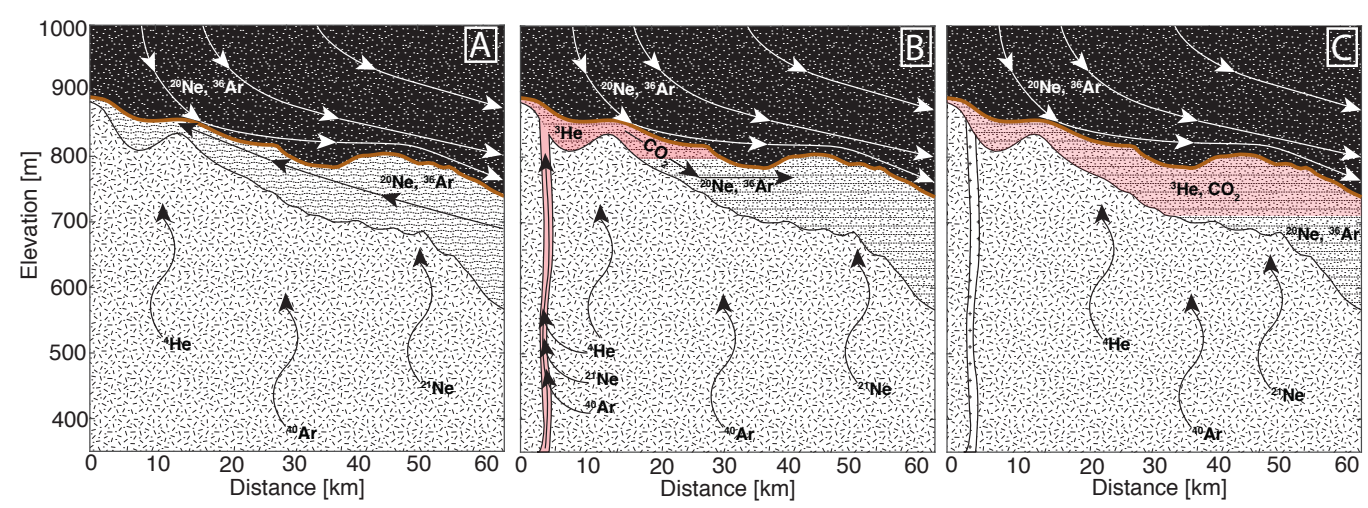

Figure 2: Noble Gas fluxes and $\mathrm{CO}_{2}$ entry event. A)Before the $\mathrm{CO}_{2}$ entry event, radiogenic gases produced in the crustal basement can only enter the Tubb sandstone via grain boundary diffusion pathways. B) During the entry of hot magmatic $\mathrm{CO}_{2}$, radiogenic gases were both carried from the mantle and swept from the crustal basement, and then deposited into the reservoir. C) After the gas entry, air-derived noble gases have been swept from the residual brine and re-dissolved into the underlying brine aquifer. ${ }^{4} \mathrm{He}^{*}$, ${ }^{40} \mathrm{Ar}^{*}$, and ${ }^{21} \mathrm{Ne}^{*}$ reaching the Tubb Sandstone through grain boundary diffusion through the underlying basement will partition and become trapped in the gas phase $\mathrm{CO}_{2}$. The noble gas compositions then act as a record of crustal degassing. 
mantle origin and was emplaced contemporaneously with basaltic volcanism, 1.2 to $1.5 \mathrm{Ma}$ [21]. Bravo Dome is located in continental crust that has been tectonically quiescent since the Ancestral Rocky Mountain orogeny, $300 \mathrm{Ma}$ [22]. Despite being located within $300 \mathrm{~km}$ of the Rio Grande rift zone, heat flow and erosion measurements show that this region is geologically similar to the stable midcontinent US $[21,8]$. There have also been a number of volcanic events in the region during the Cenozoic. However, as this study shows, even these magmatic events are insufficient to regionally evacuate noble gases from crystalline crust. The Ancestral Rocky Mountains were the sediment source for the Tubb Sandstone reservoir rock. The Tubb Sandstone has not been heated above the zircon (U-Th)/He closure temperature of roughly $180^{\circ} \mathrm{C}$ since deposition [21, 23].

The gas reservoir formed at a depth of $700 \mathrm{~m}$, directly above $1.4 \mathrm{Ga}$ granitic basement and beneath a regional anhydrite seal [24, 20] (Figure 3B). The stratigraphic location of Bravo Dome, shown in Figures 2 and 3, simplifies the potential sources and sinks of noble gases in the reservoir. Any radiogenic noble gas flux from the underlying crust will become trapped in the gas phase $\mathrm{CO}_{2}$ underneath the anhydrite seal, isolating it from the atmosphere. Furthermore, only $10 \%$ of the original $\mathrm{CO}_{2}$ has dissolved since emplacement, suggesting that there is very little background groundwater flux [21].

Three phases of fluid emplacement are illustrated in Figure 2. First, the Tubb Sandstone reservoir rock was filled with air-saturated formation brine. In the absence of groundwater recharge, radiogenic gases diffusing upward from the crust would be dissolved in the brine and trapped beneath 
the Anhydrite seal (Figure 2A). Second, during the $\mathrm{CO}_{2}$ entry event, heated mantle $\mathrm{CO}_{2}$ traveled along a fracture network through the crustal basement, liberating radiogenic ${ }^{4} \mathrm{He}^{*}$ and ${ }^{40} \mathrm{Ar}^{*}$ during its ascent. After reaching the Tubb Sandstone, the $\mathrm{CO}_{2}$ displaced the initially present formation brine, and stripped atmospheric noble gases from the residual water (Figure 2B). Finally, at present day, the radiogenic gases have been stripped from the crustal migration pathway, and the gas composition reflects a mixture of direct mantle input, crustal radiogenic gases liberated by the heat of the $\mathrm{CO}_{2}$ plume, continuous crustal degassing, and atmospheric derived noble gases which were previously dissolved in the formation brine (Figure 2C).

\subsection{Previous Estimates of Crustal Composition}

Uranium and thorium produce ${ }^{4} \mathrm{He}$ by $\alpha$-decay, while ${ }^{40} \mathrm{~K}$ produces ${ }^{40} \mathrm{Ar}$ by electron capture decay. We will refer to radiogenic, crustally produced ${ }^{4} \mathrm{He}$ and ${ }^{40} \mathrm{Ar}$ as ${ }^{4} \mathrm{He}^{*}$ and ${ }^{40} \mathrm{Ar}^{*}$. Uranium, thorium and potassium are enriched in the continental crust by a factor of 50-100 relative to the primitive mantle [25]. These radioactive isotopes are thought to be enriched in the upper crust relative to the lower crust [9]. The majority of crustal uranium and thorium is hosted by accessory minerals such as zircon, monazite and apatite, whereas potassium is dominantly hosted by feldspar.

Radioactive decay provides a significant source of heat in the Earth's crust. However, there is no consensus regarding the exact distribution of radioactive elements with depth [26]. Previous studies have encountered discrepancies between bulk estimates of crustal radioactive content and observed surface heat flux [27]. In this region, the mafic lower crust assumption is supported by surface heat measurements and mantle heat flux estimates 
$[7,8]$.

\section{Bravo Dome Noble Gas Abundances}

In order to determine the absolute quantities of each noble gas isotope in the reservoir, we interpolate previously published estimates of reservoir geometry, pore volume, bottom hole pressure, and noble gas isotope concentrations $[21,29,30]$. This volumetric calculation gives an upper bound on the total amount of radiogenic degassing that has occurred since the emplacement of the gas.

\subsection{Subtraction of Mantle Component}

Elevated gas pressure and $\mathrm{CO}_{2} /{ }^{3} \mathrm{He}$ and ${ }^{3} \mathrm{He} /{ }^{4} \mathrm{He}$ close to subcontinental lithospheric ratios confirm that the magmatic $\mathrm{CO}_{2}$ entered from the western side of the reservoir [30,21, 29], and suggest that there may be continued entry of mantle $\mathrm{CO}_{2}$. The maximum $\mathrm{CO}_{2} /{ }^{3} \mathrm{He}$ ratio in the western side of the field is $5.35 \cdot 10^{9}$, and the maximum ${ }^{3} \mathrm{He} /{ }^{4} \mathrm{He}$ ratio is $4.26 \mathrm{Ra}$ [29]. Subtracting the concentration observed closest to the gas source, we can compute the areal density of non-mantle derived noble gas,

$$
n(x, y)=\int \frac{\phi_{g}\left(c_{\mathrm{NG}}-c_{\mathrm{NG}, \mathrm{m}}\right) P_{g}}{R T} \mathrm{dz} \quad \mathrm{mols} / \mathrm{m}^{2} .
$$

The concentration of each noble gas measured near the gas source, $c_{\mathrm{NG}, \mathrm{m}}$, is assumed to be the mantle input composition, due to MORB ${ }^{3} \mathrm{He} /{ }^{4} \mathrm{He}$ ratios in this area. The noble gas concentration at a particular location in the reservoir is given by $c_{\mathrm{NG}}$, and is shown in Figures $4 \mathrm{~A}, 4 \mathrm{C}, 4 \mathrm{E}$, and $4 \mathrm{G}$. These figures show a kriging interpolation of previously published noble 

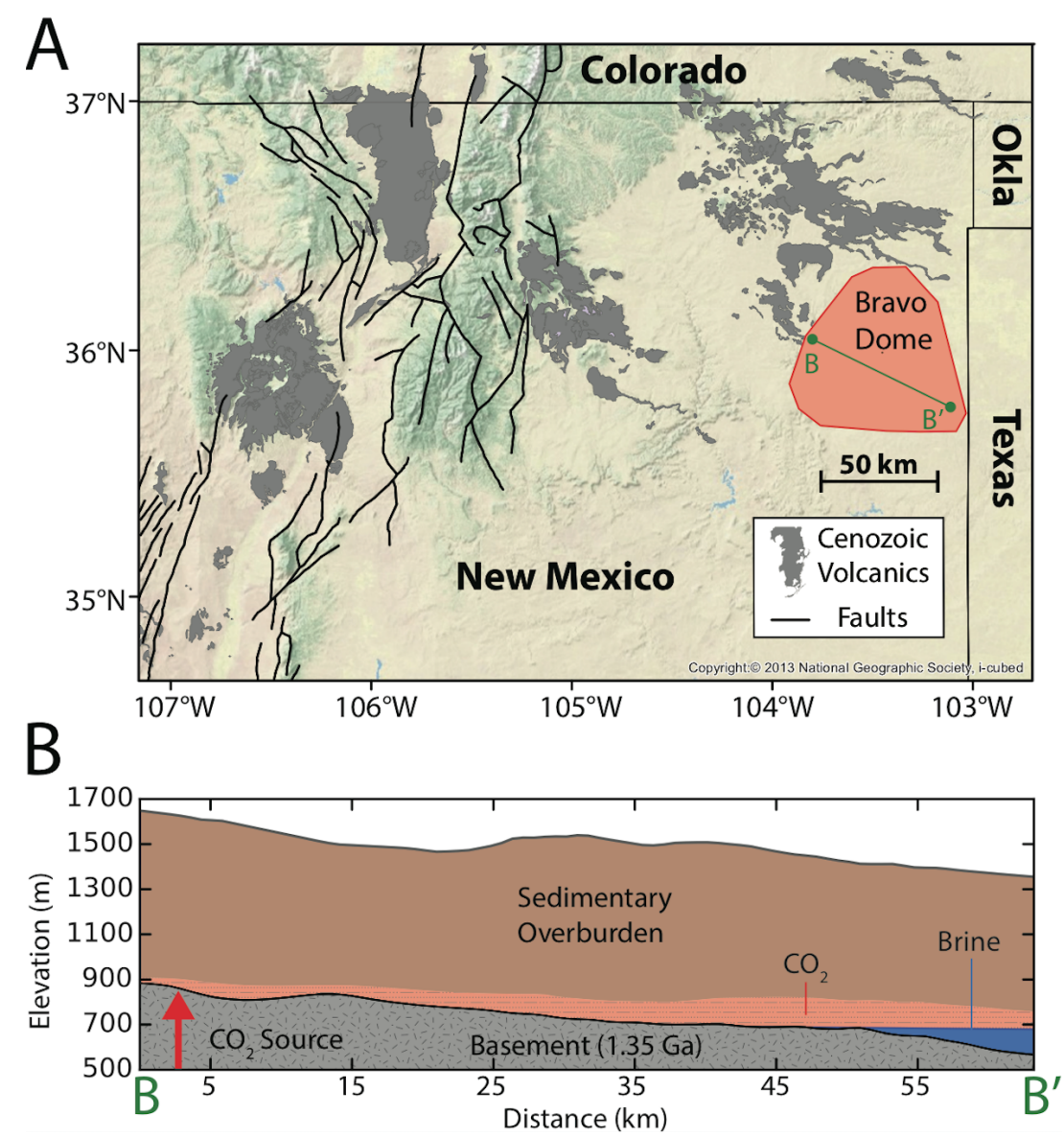

Figure 3: (A) Bravo Dome reservoir, surface volcanic outcrops, and faults associated with the Rio Grande rift [28]. The mantle $\mathrm{CO}_{2}$ in the reservoir is thought to be associated with Cenozoic volcanism. (B) Reservoir cross section. The gas directly overlies the Precambrian crystalline basement and is sealed by the Cimarron Anhydrite, allowing the gas phase to effectively partition and trap any crustal degassing. 
gas concentrations [29]. Sample locations are shown as white squares. The measured gas pressure before commercial production in 1981 is $P_{g}$, and $\phi_{g}$ is the volume fraction of gas at a location in the reservoir. The areal density $n(x, y)$ indicates the number of mols per square meter of each isotope at a given location, integrated vertically over the entire gas column (Figures 4B, $4 \mathrm{D}, 4 \mathrm{~F}$, and $4 \mathrm{H})$.

Integrating the areal density over the area of the reservoir gives the total number of non-mantle mols of each noble gas,

$$
N=\iint n(x, y) \mathrm{dxdy} \text { mols. }
$$

Combining the interpolation uncertainties of the gas volume fraction $\phi_{g}$, gas density $\rho$, gas thickness $H_{g}$, and isotope concentration $c_{\mathrm{NG}}$, we compute the uncertainty in the areal density of each isotope,

$$
\sigma_{n}^{2}=\left[\left(\frac{\sigma_{H_{g}}}{H_{g}}\right)^{2}+\left(\frac{\sigma_{\phi}}{\phi}\right)^{2}+\left(\frac{\sigma_{\rho}}{\rho}\right)^{2}+\left(\frac{\sigma_{f}}{f}\right)^{2}\right] n^{2}
$$

The total abundance and associated uncertainty of each noble gas are given in Table 1. The uncertainties in the noble gas abundances are substantial, approximately $\pm 50 \%$. Most of the uncertainty is induced by the reservoir geometry and affects all isotopic abundances equally. Therefore, the uncertainty of ratios of total abundances is very small.

\subsection{Atmospheric Component}

Using the non-radiogenic isotopes ${ }^{20} \mathrm{Ne},{ }^{36} \mathrm{Ar}$, and ${ }^{84} \mathrm{Kr}$, we can estimate the input of noble gases from the pre-emplacement air-saturated water in the formation. We estimate the equivalent volumes of air-saturated water 
Bravo Dome Non-Radiogenic (Atmospheric) Noble Gas Isotopes

\begin{tabular}{|c|c|c|c|c|}
\hline Isotope & Total Mols & Non-Mantle Mols & $\mathrm{V}_{\mathrm{ASW}}$ & $\mathrm{V}_{r w}$ Volumes \\
\hline${ }^{20} \mathrm{Ne}$ & $6 \pm 3000$ & 3100 & $0.4 \mathrm{~km}^{3}$ & 0.05 \\
${ }^{36} \mathrm{Ar}$ & $(1.1 \pm 0.5) \cdot 10^{5}$ & $7.7 \cdot 10^{4}$ & $1.7 \mathrm{~km}^{3}$ & 0.2 \\
${ }^{84} \mathrm{Kr}$ & $410 \pm 190$ & 250 & $0.16 \mathrm{~km}^{3}$ & 0.02 \\
\hline
\end{tabular}

Bravo Dome Radiogenic (Crustal) Noble Gas Isotopes

\begin{tabular}{|c|c|c|c|c|}
\hline Isotope & Total Mols & Non-Mantle Mols & $\mathrm{V}_{\mathrm{ASW}}$ & $\mathrm{V}_{r w}$ Volumes \\
\hline${ }^{4} \mathrm{He}$ & $(3.4 \pm 1.5) \cdot 10^{8}$ & $2.3 \cdot 10^{8}$ & $1.2 \cdot 10^{5} \mathrm{~km}^{3}$ & $1.3 \cdot 10^{4}$ \\
${ }^{21} \mathrm{Ne}$ & $38 \pm 17$ & 21 & $0.9 \mathrm{~km}^{3}$ & 0.1 \\
${ }^{40} \mathrm{Ar}$ & $(11 \pm 5) \cdot 10^{8}$ & $2.6 \cdot 10^{8}$ & $20 \mathrm{~km}^{3}$ & 2.2 \\
\hline
\end{tabular}

Table 1: Quantities of total and non-mantle derived noble gases in the Bravo Dome natural $\mathrm{CO}_{2}$ field. $\mathrm{V}_{\mathrm{ASW}}$ refers to the volume of air-saturated water containing the observed number of non-mantle mols. The gas reservoir contains $9 \mathrm{~km}^{3}$ of residual water $\left(\mathrm{V}_{r w}\right)$, while the atmospheric gas quantities correspond to less than $2 \mathrm{~km}^{3}$ of degassed air-saturated water $\left(\mathrm{V}_{\text {ASW }}\right)$. This finding is in agreement with the two-stage fractionation model of [30]. 
required to provide the observed amount of noble gases in the gas phase, given by

$$
V_{\mathrm{ASW}}=\frac{N}{P_{\mathrm{atm}, \mathrm{NG}} K_{\mathrm{NG}}},
$$

where $P_{\text {atm,NG }}$ is the partial pressure of each noble gas in the atmosphere and $K_{\mathrm{NG}}$ is the Henry's law coefficient.

The reservoir model of Bravo Dome indicates that the gas cap shown in Figure 3B has a pore volume of $23 \mathrm{~km}^{3}$ [21]. The silt within this gas cap still contains $9 \mathrm{~km}^{3}$ of brine that will be referred to as residual water, $V_{r w}$, below. Assuming equilibrium partitioning of components between gas and water, Table 1 shows that the observed abundances of non-radiogenic atmospheric isotopes represent degassed volumes of air-saturated water, $V_{\mathrm{ASW}}$, much less than $\mathrm{V}_{r w}$. The low abundance of atmospheric isotopes shows that the emplacement stripped the residual water of dissolved gases, as previously suggested in the two stage dissolution model of [30].

\subsection{In-Situ Production of ${ }^{4} \mathrm{He}^{*}$}

In order to estimate the maximum contribution of in-situ production of ${ }^{4} \mathrm{He}^{*}$ within the Tubb Sandstone, we assume concentrations of uranium and thorium equal to literature values for the upper crust. This gives uranium and thorium concentrations of $2.8 \mathrm{ppm}$ and $11.2 \mathrm{ppm}$ [9]. By multiplying the uranium and thorium concentrations by porosity and gas thickness, we compute the maximum quantity of a given radioactive isotope, $i$, in the Bravo Dome reservoir. The molar mass of the isotope is given by $M_{i}$, the mass fraction in the sediment is $c_{i}$, and the total number of mols in the sediment is 

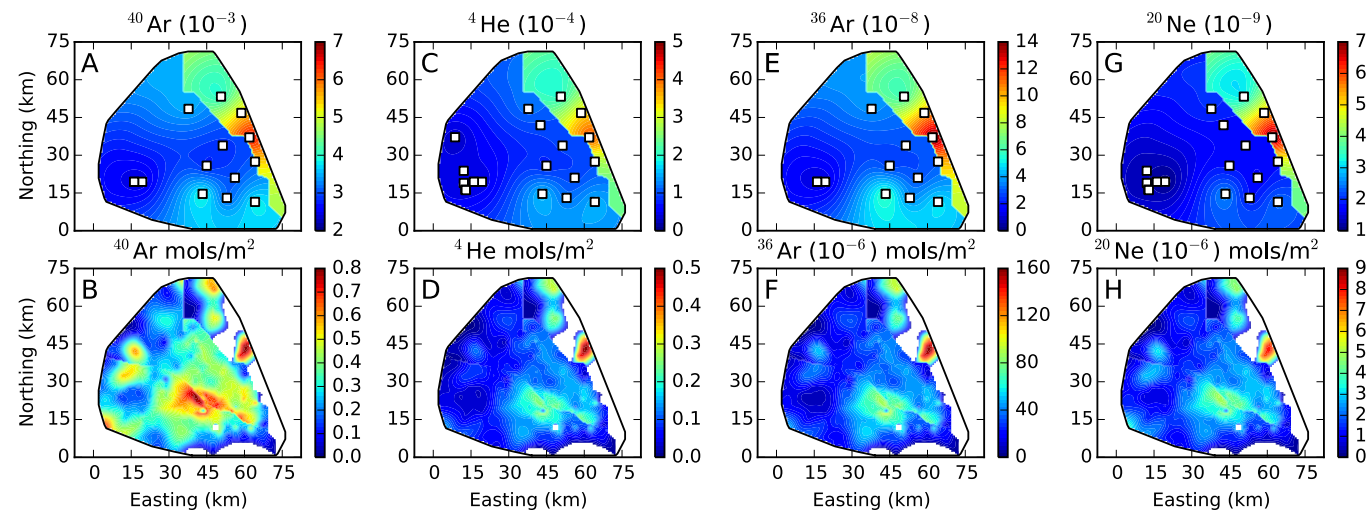

Figure 4: Concentration and areal density plots of ${ }^{40} \mathrm{Ar},{ }^{4} \mathrm{He},{ }^{36} \mathrm{Ar}$, and ${ }^{20} \mathrm{Ne}$ in the Bravo Dome reservoir, computed using Kriging interpolations on either side of a fault. The mantle component is removed by uniformly subtracting a concentration equal to the lowest concentration in the west. White squares indicate wells sampled for a given noble gas [29]. The top shows the interpolated gas phase concentration of noble gases. The bottom shows the areal density of the noble gases in the gas phase. (A, B) ${ }^{40} \mathrm{Ar},(\mathbf{C}, \mathbf{D})$ ${ }^{4} \mathrm{He},(\mathbf{E}, \mathbf{F}){ }^{36} \mathrm{Ar},(\mathbf{G}, \mathbf{H}){ }^{20} \mathrm{Ne}$. 


$$
\mathrm{N}_{\mathrm{i}, \mathrm{sed}}=\left(\frac{c_{i} \rho}{M_{i}}\right) \iiint(1-\phi) \mathrm{dxdydz} .
$$

These calculations show that the sediment contains a maximum of $4.4 \cdot 10^{9}$ mols of ${ }^{238} \mathrm{U}, 1.8 \cdot 10^{10} \mathrm{mols}$ of ${ }^{232} \mathrm{Th}$, and $4.2 \cdot 10^{8}$ mols of ${ }^{235} \mathrm{U}$.

Because the zircon (U-Th)/He ages in the Tubb Sandstone preserve detrital ages, we assume that the only ${ }^{4} \mathrm{He}^{*}$ from the sediment that has entered the gas is the ${ }^{4} \mathrm{He}^{*}$ that is directly ejected from minerals [21]. The fraction retained, known as the $F_{T}$ correction, was computed for several Tubb sandstone zircons [21, 31]. For the calculation of in-situ ${ }^{4} \mathrm{He}$ production, we assume an $F_{T}$ correction of 0.80 , meaning that $80 \%$ of the produced ${ }^{4} \mathrm{He}$ has been retained in the mineral grains. This value for the $F_{T}$ correction falls in the range computed for four Tubb Sandstone zircons [21]. Over the roughly 250Ma since the end of the Permian, we calculate that the total ${ }^{4} \mathrm{He}^{*}$ released into the Bravo Dome pore fluid from ${ }^{238} \mathrm{U},{ }^{235} \mathrm{U}$, and ${ }^{232} \mathrm{Th}$ is $5.6 \cdot 10^{8}$ mols.

This quantity of ${ }^{4} \mathrm{He}^{*}$ is greater than the total measured amount of ${ }^{4} \mathrm{He}$ in the reservoir, 3.5.10 mols. However, this calculation assumes that the groundwater in the shallow Tubb Sandstone, currently at $700 \mathrm{~m}$ depth, has been stagnant and retentive of ${ }^{4} \mathrm{He}$ for 250 Ma. Additionally, atmospheric derived isotopes suggest that a small fraction of the pre-emplacement dissolved noble gas isotopes in the formation brine are currently present in the Bravo Dome gas, because they were swept by the gas plume and redissolved into the underlying brine [30].

The volumes of atmospheric derived noble gases in Bravo Dome correspond to between 0.02 and 0.2 residual water volumes (Table 1). Therefore, ${ }^{20} \mathrm{Ne} V_{\mathrm{ASW}}$ values show that only about $2 \%$ of the pre-emplacement dissolved 
volatile gas in the formation brine is present in the Bravo Dome gas today. Assuming a comparable amount of ${ }^{4} \mathrm{He}^{*}$ is retained, this would lead to a maximum in-situ remaining ${ }^{4} \mathrm{He}^{*}$ quantity of $0.02 \cdot{ }^{4} \mathrm{He}_{\mathrm{FT}}=1.1 \cdot 10^{7}$ mols. If $100 \%$ of the in-situ production of ${ }^{4} \mathrm{He}^{*}$ remained trapped in the groundwater system without being advected away or vented to the atmosphere in the last $250 \mathrm{Ma}$, pre-emplacement dissolved ${ }^{4} \mathrm{He}^{*}$ can only account for a maximum of $3 \%$ of the observed $3.5 \cdot 10^{8}$ mols of non-mantle ${ }^{4} \mathrm{He}$ in the gas phase.

\subsection{In-Situ Production of ${ }^{40} A r^{*}$}

The closure temperatures for ${ }^{40} \mathrm{Ar}^{*}$ in feldspar, biotite, and muscovite are all above $200^{\circ} \mathrm{C}[32]$. Because the Tubb Sandstone zircons have never been reset since deposition [21], we assume that the ${ }^{40} \mathrm{Ar}^{*}$ production within the sediment remains trapped within mineral grains. As an upper bound, we use the bulk upper crust estimate of $\mathrm{K}_{2} \mathrm{O}$ content of $3.4 \%$, leading to a total potassium estimate of $2.7 \cdot 10^{14}$ mols, and the ${ }^{40} \mathrm{~K}$ total of $3.2 \cdot 10^{10}$ mols [9]. After $250 \mathrm{Ma}$, this amount of ${ }^{40} \mathrm{~K}$ will produce $7.6 \cdot 10^{8}$ mols of ${ }^{40} \mathrm{Ar}^{*}$ within the Tubb Sandstone reservoir rock.

Since the end of the Permian, the total amount of ${ }^{40} \mathrm{Ar}^{*}$ produced in the Tubb Sandstone sediment, $11 \cdot 10^{8}$ mols, is similar to the total ${ }^{40} \mathrm{Ar}$ found in the Bravo Dome gas field. To estimate the maximum amount of the in-situ produced ${ }^{40} \mathrm{Ar}^{*}$ that could be in the gas phase, we assume that all produced ${ }^{40} \mathrm{Ar}^{*}$ was dissolved in the brine before $\mathrm{CO}_{2}$ emplacement. The fraction of this ${ }^{40} \mathrm{Ar}$ that has partitioned from the brine into the gas phase is similar to the fraction of ${ }^{36} \mathrm{Ar}$, approximately $20 \%$. The maximum amount of in-situ produced ${ }^{40} \mathrm{Ar}^{*}$ in the gas phase is $1.5 \cdot 10^{8}$ mols, which constitutes less than $15 \%$ of the total reservoir ${ }^{40} \mathrm{Ar}$. 


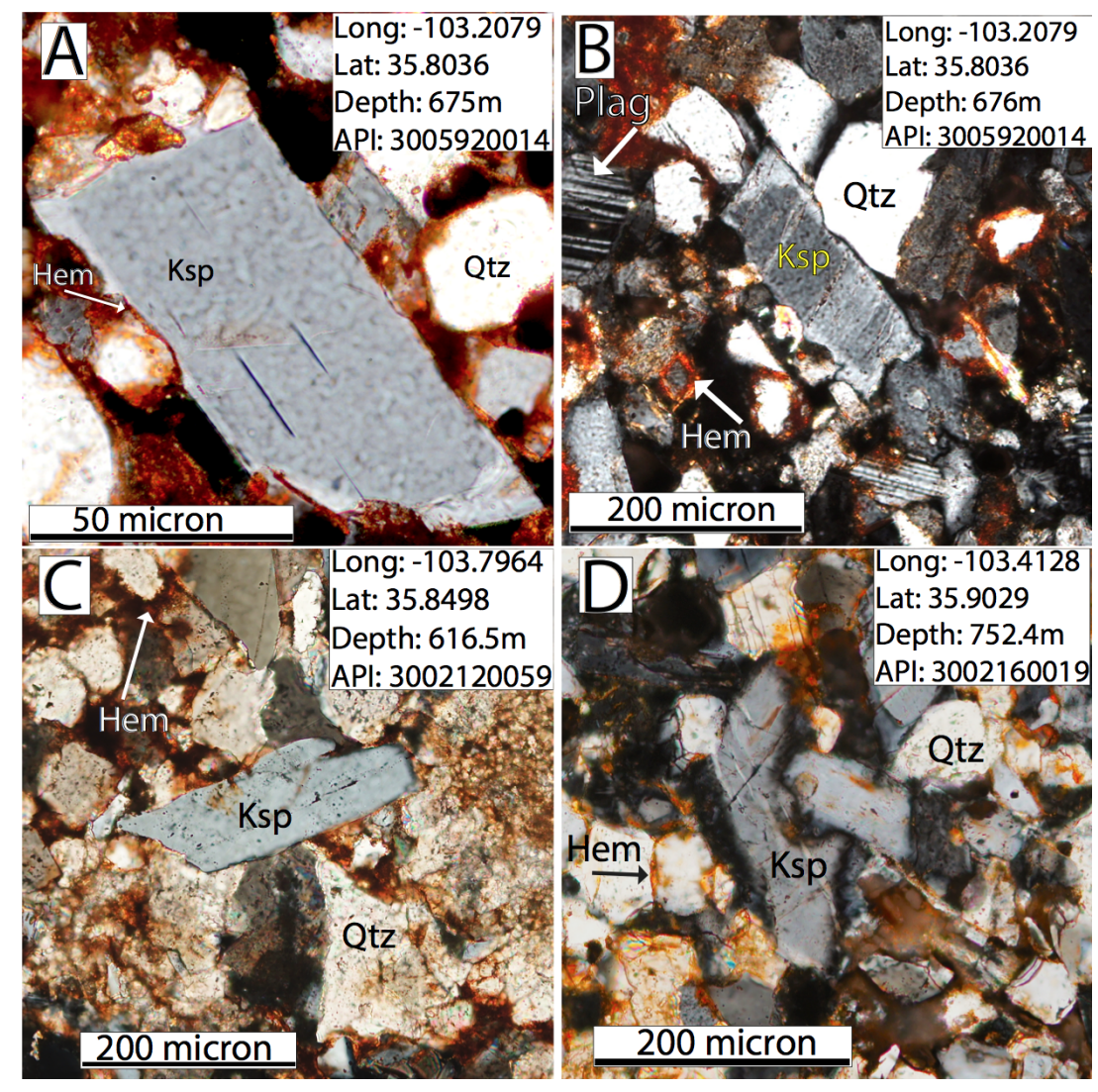

Figure 5: Thin-section photomicrographs of detrital components and diagenetic features in Tubb sandstone reservoir rock. All photos taken in cross-polarised light. A) Close-up of K-feldspar grain in arkosic sandstone matrix. Note pervasive hematite cement along grain boundaries and tight packing of quartz matrix. K-feldspar grain boundaries are largely undisturbed and show few concave portions indicative of pressure dissolution. B) Typical arkosic sandstone. K-feldspar grain maintains elongate grain boundaries. C) and D) Kfeldspar in well-sorted arkosic sandstones. Note, in D), the dense packing structure of the quartz matrix and evidence for pressure dissolution along K-feldspar grain boundary. 
However, in situ production as the source of the ${ }^{40} \mathrm{Ar}^{*}$ in the gas would require widespread breakdown of the feldspars and mica in the sediment. While photomicrographs show some evidence of pressure dissolution during compaction and cementation of the sandstone matrix, subsequent dissolution appears to be minor (Figure 5).

\subsection{Comparison with interpretations based on noble gas isotope ratios}

Previous studies have made extensive use of noble gas isotope ratios of subsurface gas samples to determine gas sourcing and interaction with groundwater [33, 30]. In contrast, we examine estimates of absolute noble gas abundances obtained from geostatistical interpolation of point estimates and a detailed reservoir model. Previous interpretation of the discrete measurements of the ${ }^{20} \mathrm{Ne} /{ }^{36} \mathrm{Ar}$ and ${ }^{20} \mathrm{Ne} /{ }^{84} \mathrm{Kr}$ ratios in Bravo Dome suggested that the $\mathrm{CO}_{2}$ plume stripped atmospheric noble gases from the pre-emplacement formation brine, which then re-dissolved after the $\mathrm{CO}_{2}$ entry continued. Our calculations of the total noble gas abundance in the gas plume supports this interpretation. Table 1 shows that the total abundances of the atmospheric gases ${ }^{20} \mathrm{Ne},{ }^{36} \mathrm{Ar}$, and ${ }^{84} \mathrm{Kr}$ are between $2 \%$ and $20 \%$ of the quantities predicted by degassing of the residual water in the gas cap.

\subsection{Noble Gas Totals}

The volumes of air saturated water required to account for all of the non-mantle ${ }^{4} \mathrm{He}$ and ${ }^{40} \mathrm{Ar}$ shows that roughly $10 \%$ of the non-mantle ${ }^{40} \mathrm{Ar}$ and $4 \mathrm{ppm}$ of the non-mantle ${ }^{4} \mathrm{He}$ is sourced from the atmosphere, with the remainder sourced from crustal production (Table 1). Due to the low total abundance, we cannot deconvolve ${ }^{21} \mathrm{Ne}$ contributions from the mantle, 
crust, and atmosphere. The Bravo Dome crustal ratio, ${ }^{4} \mathrm{He}^{*} /{ }^{40} \mathrm{Ar}^{*} \approx 1$, is much lower than the bulk crustal production ratio of ${ }^{4} \mathrm{He}^{*} /{ }^{40} \mathrm{Ar}$, which varies between 4 and 8 [33]. This discrepancy can be explained by several hypotheses: $a$ ) differing accumulation ages, $b$ ) differing source volumes, $c$ ) enrichment of ${ }^{40} \mathrm{~K}$ in the noble gas source rocks, or $d$ ) fractionation during or after emplacement.

\section{Geotherm and Radioactive Content}

In order to estimate the radiogenic production of ${ }^{4} \mathrm{He}^{*}$ and ${ }^{40} \mathrm{Ar}^{*}$ in the underlying crustal basement beneath Bravo Dome, we use surface heat flux measurements and a seismic density profile to constrain the temperature, heat flux, and total radioactive content $[34,8]$. The resulting profiles are shown in Figure 6. The geotherm calculated below assumes a high temperature at the base of the crust. The diffusive fluxes calculated below are thereby maximum estimates.

\subsection{Heat Flux and Composition}

Crustal radioactivity produces heat along with ${ }^{4} \mathrm{He}^{*}$ and ${ }^{40} \mathrm{Ar}^{*}$. The total crustal heat generation in this region is equal to the difference between the mantle heat flux of $28 \mathrm{~mW} / \mathrm{m}^{2}$ and the surface heat flux of $58 \mathrm{~mW} / \mathrm{m}^{2}$, as shown in Figure 6A [7,8]. We use the density profile of the crust (Figure 6B) to estimate the amount of U, Th, and K with depth [34]. Felsic upper crust has a density of $2700\left[\mathrm{~kg} / \mathrm{m}^{3}\right]$ and mafic lower crust has a density of 3000 $\left[\mathrm{kg} / \mathrm{m}^{3}\right][35]$. Therefore, we compute the fraction of felsic crust with depth,

$$
f(z)=\frac{\rho(z)-3000}{2700-3000}
$$




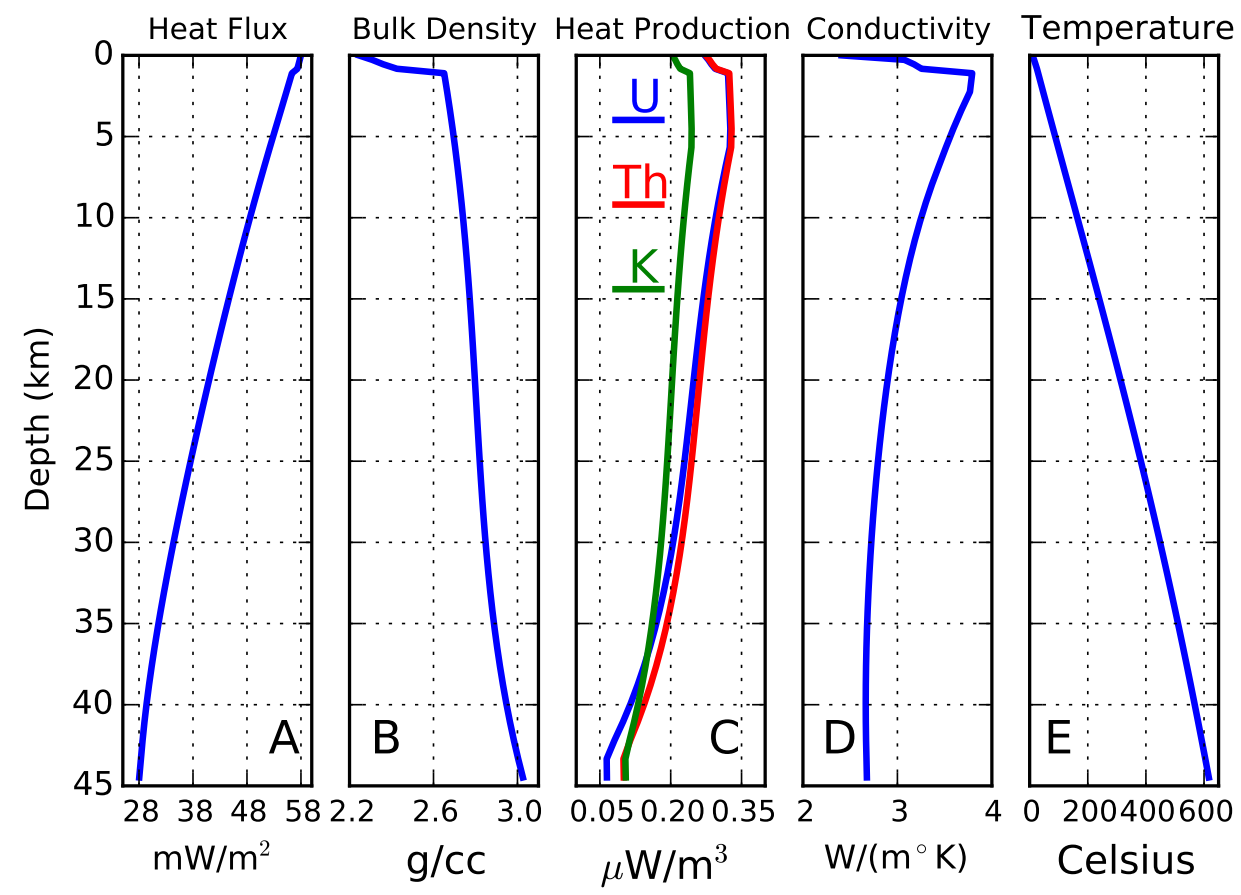

Figure 6: (A) Calculated crustal heat flux, constrained by surface and mantle fluxes $[8,7]$. (B) Crustal density profile derived from seismology [34]. (C) Calculated heat production beneath Bravo Dome, split into contributions from ${ }^{40} \mathrm{~K}$, uranium, and thorium and constrained by surface heat flux. (D) Calculated thermal conductivity, which varies inversely with temperature for both mafic and felsic end members. (E) Calculated geothermal profile beneath Bravo Dome. 
where $\rho(z)$ is the density profile estimated from seismic data [34]. While this mapping from density to composition is overly simplified, it does provide first-order information about the distribution of mineralogy with depth. Figure 6B shows a gradual increase of the mafic component with depth and no clear transition from felsic upper to mafic lower crust. We use literature values for uranium, thorium, and $\mathrm{K}_{2} \mathrm{O}$ mass fractions in the lower crust [9]. We then compute the felsic upper crustal heat production required to match the observed surface heat flow [8]. Upper crustal uranium and thorium concentrations are estimated from the heat production by varying the $\mathrm{K}_{2} \mathrm{O}$ between the published middle and upper crustal concentrations [9]. The decays of ${ }^{238} \mathrm{U},{ }^{235} \mathrm{U},{ }^{232} \mathrm{Th}$, and ${ }^{40} \mathrm{~K}$ emit different amounts of energy. The ${ }^{40} \mathrm{~K} \beta$-decay energy is approximately 50 times smaller than the multiple $\alpha$ decays of uranium and thorium [36]. This effect makes the heat production from uranium and thorium larger than the production from potassium (Figure 6C).

Heat flux constraints show that the total crustal radioactive content in northeastern New Mexico is less than literature values for bulk crust $[9,7,8]$. Figure 7 shows upper crustal uranium and thorium mass fractions computed from the heat flux beneath Bravo Dome, along with several measurements of uranium and thorium content from drill cores in the nearby Texas Panhandle basement. The computed upper crustal uranium and thorium fractions are similar to measured values of quartz monzonite and granite, although much lower than measurements from rhyolite and trachyte [24, 9]. For the radiogenic gas and heat production assumptions used in this study, we use upper crustal radioactive element concentrations corresponding to the up- 


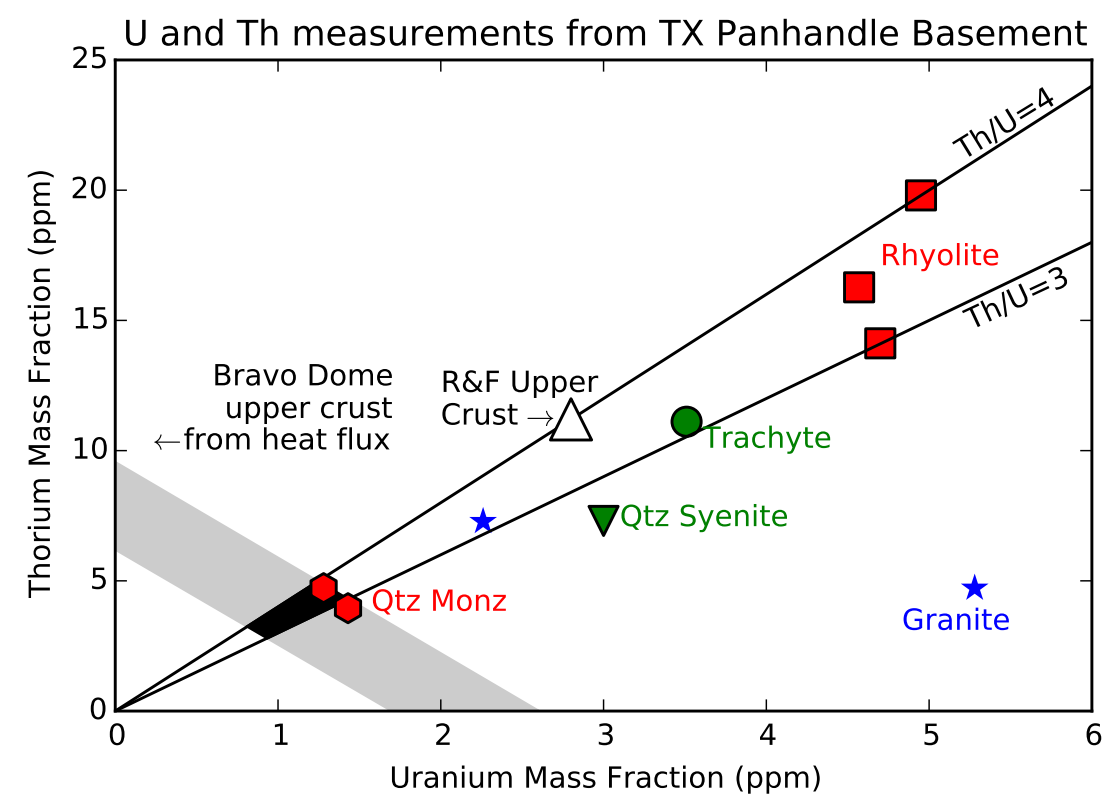

Figure 7: Bravo Dome upper crustal radioactive composition estimates from heat flow together with nearby basement samples [24]. The gray area shows the possible values for $\mathrm{U}$ and Th, given an upper crustal $\mathrm{K}_{2} \mathrm{O}$ range between $1.8 \%$ and $3.4 \%$. Uranium and thorium upper crustal values fall near measured values of quartz monzonite in this region, but are well below global averages denoted as R\&F Upper Crust [9].

per corner of the black area shown in Figure 7. This point corresponds to lower than bulk upper crustal estimates for uranium, thorium, and potassium concentrations.

\subsection{Thermal Conductivity}

Thermal conductivity varies inversely with temperature and is given by

$$
k_{j}(T)=A_{j}+\frac{B_{j}}{350+T\left({ }^{\circ} \mathrm{C}\right)}\left[\frac{\mathrm{W}}{\mathrm{m}^{\circ} \mathrm{K}}\right]
$$

where the coefficients $A_{j}$ and $B_{j}$ refer to the coefficients for the felsic or mafic end members [37]. To match the observed surface heat flux and to remain 
below the crustal solidus, we use $A_{f}$ of $1.64 \mathrm{~W} /\left(\mathrm{m}^{\circ} \mathrm{K}\right), A_{m}$ of $2.18 \mathrm{~W} /\left(\mathrm{m}^{\circ} \mathrm{K}\right)$, $B_{f}$ of $807 \mathrm{~W} / \mathrm{m}$, and $B_{m}$ of $474 \mathrm{~W} / \mathrm{m}$. Mixing the two conductivity values using (6) we can obtain conductivity as a function of temperature and composition

$$
k(f, T)=f k_{f}(T)+(1-f) k_{m}(T) \quad\left[\frac{\mathrm{W}}{\mathrm{m}^{\circ} \mathrm{K}}\right] .
$$

In the shallow sedimentary portions of the crust, we compute the porosity from density, and assume the pore space to be filled with water. We then compute the conductivity as a mixture of sediment and water. The thermal conductivity profile is plotted in Figure 6D.

\subsection{Solution for Temperature}

Heat production is equal to the derivative of heat flux,

$$
\frac{d q}{d z}=-H(z)
$$

The heat production of a given radioactive isotope $i$ with a decay constant $\lambda_{i}$ is given by

$$
H_{i}(z)=E_{i} \lambda_{i} r_{i} \rho(z) \quad\left[\mathrm{W} / \mathrm{m}^{3}\right]
$$

where $E_{i}$ is the energy released by one decay of isotope $i, r_{i}$ is the concentration of $i$ in the rock, and $\rho(z)$ is the density at depth $z$.

Because conductivity and temperature are co-dependent, we iteratively solve the thermal diffusion equation for temperature as a function of depth (Figure 6E). First, we use the known surface conductivity, $k_{s}$, and heat flux, $q_{s}$, to determine the surface temperature gradient, 


$$
\left.\frac{d T}{d z}\right|_{z=0}=\frac{-q_{s}}{k_{s}} .
$$

We then numerically solve for the temperature towards the bottom of the crust.

\section{Grain Boundary Diffusion Model}

Two end-member transport scenarios may account for the release of the crustal radiogenic noble gas inventory beneath Bravo Dome: $i$. advection of noble gases by a migrating fluid phase, and $i$. diffusion of the noble gases along grain boundaries. To test whether diffusion is a viable transport mechanism for crustal degassing, we calculate the maximum diffusive flux of ${ }^{4} \mathrm{He}^{*}$ and ${ }^{40} \mathrm{Ar}^{*}$.

In order to estimate a maximum possible diffusive flux of ${ }^{4} \mathrm{He}^{*}$ and ${ }^{40} \mathrm{Ar}^{*}$ from the crust, we solve the diffusion equation with radioactive production of ${ }^{4} \mathrm{He}^{*}$ and ${ }^{40} \mathrm{Ar}^{*}$ over a $1 \mathrm{D}$ crustal column. The production term in this equation is calibrated using the heat flow constraints established in the previous section. The heat flux constraint leads to upper crustal U, Th, and $\mathrm{K}_{2} \mathrm{O}$ values of $1.13 \mathrm{ppm}, 4.4 \mathrm{ppm}$, and $1.6 \%$. Lower crustal values are taken from literature, and are set to $0.2 \mathrm{ppm}, 1.2 \mathrm{ppm}$, and $0.6 \%$ [9].

In order to estimate the maximum possible flux, we assume that grain boundaries are represented by $1 \%$ water-saturated porosity, $\phi$. We then use established data for the diffusivity of helium and argon in water, and compute the concentration profile of ${ }^{4} \mathrm{He}^{*}$ and ${ }^{40} \mathrm{Ar}^{*}$ in crustal grain boundaries after 1.5 Ga. The diffusion coefficient is dependent on temperature and estimated using an Arrhenius relationship from experimental data [38, 39]. The 
diffusion-production equation is solved numerically, with $C_{i}$ representing the ${ }^{4} \mathrm{He}^{*}$ or ${ }^{40} \mathrm{Ar}^{*}$ concentration on the grain boundaries

$$
\begin{gathered}
\frac{\partial C_{i}}{\partial t}=-\frac{\phi}{\tau} \frac{\partial}{\partial z}\left(D(z) \frac{\partial C_{i}}{\partial z}\right)+G_{i}(z, t) \\
\left.\frac{d C_{i}}{d z}\right|_{z=45 k m}=0 \quad \text { and }\left.\quad C\right|_{z=0}=0
\end{gathered}
$$

$G_{i}(z, t)$ represents the radioactive production of the noble gas $i . G_{i}(z, t)$ is related to the heat production terms defined in the previous section. Each decay of ${ }^{238} \mathrm{U},{ }^{235} \mathrm{U}$, and ${ }^{232} \mathrm{Th}$ produces 8,7 , and $6{ }^{4} \mathrm{He}^{*}$ atoms respectively. The decay of ${ }^{40} \mathrm{~K}$ is branched, such that only $11 \%$ of ${ }^{40} \mathrm{~K}$ decays produce an atom of ${ }^{40} \mathrm{Ar}^{*}[40]$. The grain boundary tortuosity $\tau$ is prescribed to be $\sqrt{2}$. For the ${ }^{4} \mathrm{He}^{*}$ system, we assume that $20 \%$ of the ${ }^{4} \mathrm{He}^{*}$ produced below the zircon closure temperature reaches the grain boundaries through direct $\alpha$ ejection, leading to a sharp reduction in ${ }^{4} \mathrm{He}^{*}$ production reaching the grain boundaries in the shallow area below $180^{\circ} \mathrm{C}[23,31]$. Other uranium and thorium bearing minerals such as apatite and monazite will release ${ }^{4} \mathrm{He}^{*}$ at lower temperatures, and these effects are accounted for in the partial ${ }^{4} \mathrm{He}^{*}$ release in the shallow regions [40]. In the case of ${ }^{40} \mathrm{Ar}^{*}$, we assume that all ${ }^{40} \mathrm{Ar}^{*}$ is retained within mineral grains below $250^{\circ} \mathrm{C}[32]$. Model calculations (Figure 8A, 8B), show that diffusive migration accounts for the loss of less than $1 \%$ of the total ${ }^{4} \mathrm{He}^{*}$ and ${ }^{40} \mathrm{Ar}^{*}$ produced over $1.5 \mathrm{Ga}$ within a crustal column.

The diffusion model shows that diffusive mass transport alone cannot explain the abundances of radiogenic noble gases observed in Bravo Dome. This suggests that tectonically quiescent crust retains noble gases. The noble 

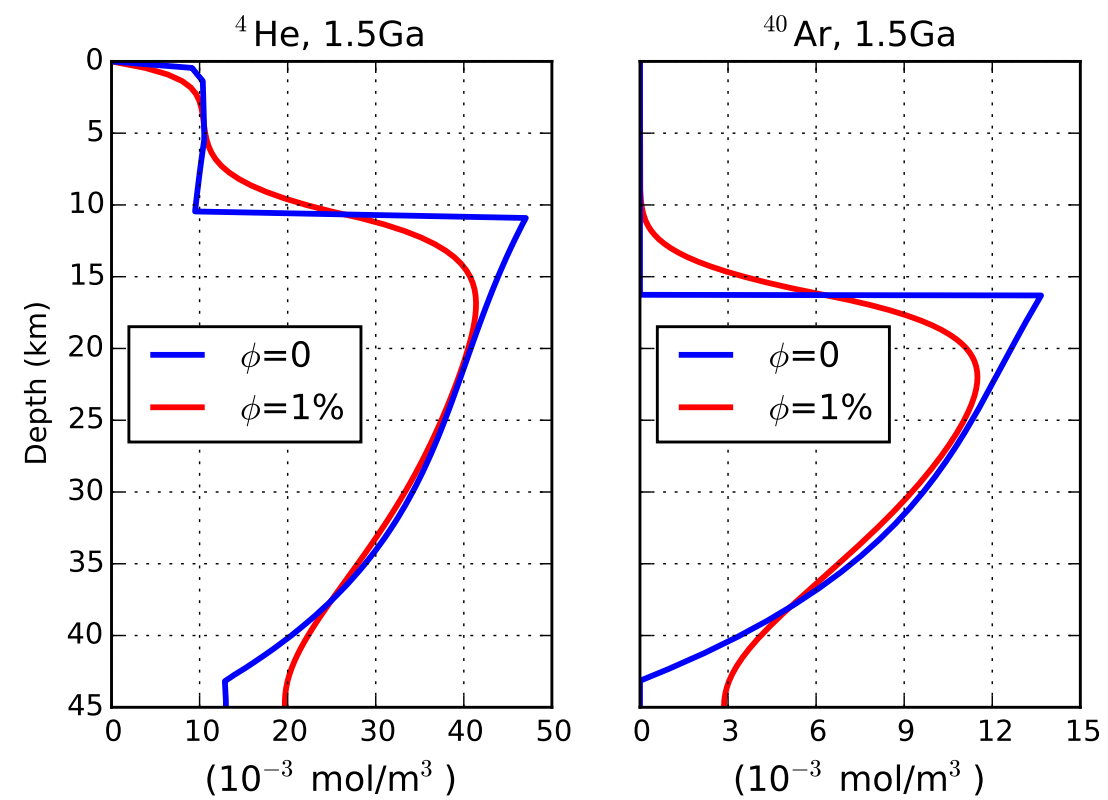

Figure 8: Diffusion models for (A) ${ }^{4} \mathrm{He}$ and (B) ${ }^{40} \mathrm{Ar}$. In the shallow crust, ${ }^{4} \mathrm{He}^{*}$ and ${ }^{40} \mathrm{Ar}^{*}$ are trapped within $\mathrm{U}$, Th, and $\mathrm{K}$ bearing minerals. Above $180^{\circ} \mathrm{C}$ and $260^{\circ} \mathrm{C}$ respectively, ${ }^{4} \mathrm{He}^{*}$ and ${ }^{40} \mathrm{Ar}^{*}$ diffuse out of minerals and into grain boundaries, where they are free to diffuse to the atmosphere. We show two extreme cases, one with $0 \%$ connected porosity and subsequently no diffusive transport (blue), and a case with a uniform crustal porosity of $1 \%$ (red). Even with $1 \%$ porosity, the diffusive flux of radiogenic gases to the atmosphere is negligible, less than $1 \%$ of the total produced over 1.5 Ga.

gases were likely mobilized by the hot magmatic $\mathrm{CO}_{2}$ entry event which formed Bravo Dome, 1.5 Ma. At present, the gas sampled at the $\mathrm{CO}_{2}$ entry point has an elevated pressure and has reverted to a mantle isotope signature $[21,30]$. This composition is likely due to the purging of radiogenic noble gases from the migration pathway. Noble gas advective transport at Bravo Dome corroborates previous findings that advective fluid events are required to mobilize ${ }^{4} \mathrm{He}$ in the crust $[41,19]$. 


\section{Crustal Volume Swept by $\mathrm{CO}_{2}$ Event}

Using the concentrations of $\mathrm{U}, \mathrm{Th}$, and $\mathrm{K}$ derived from the heat flux and seismic profiles, we can make an estimate of the radiogenic production of ${ }^{4} \mathrm{He}^{*}$ and ${ }^{40} \mathrm{Ar}^{*}$. This leads to a bulk crustal production ratio ${ }^{4} \mathrm{He}^{*} /{ }^{40} \mathrm{Ar}^{*} \approx 5$. Figure $8 \mathrm{~A}$ and $8 \mathrm{~B}$ show the grain boundary concentration of ${ }^{4} \mathrm{He}^{*}$ and ${ }^{40} \mathrm{Ar}^{*}$ after $1.5 \mathrm{Ga}$ as a function of depth, assuming no loss to the atmosphere.

In order to estimate the volume and ages of crust required to produce the observed quantities of crustal ${ }^{4} \mathrm{He}^{*}$ and ${ }^{40} \mathrm{Ar}^{*}$, we use the crustal concentrations of $\mathrm{U}$, Th, and $\mathrm{K}$ computed from the surface heat flux, average over the entire crustal column, and integrate over the accumulation time, $t_{a c c}$,

$$
V\left(t_{a c c}\right)=\left(\frac{N \text { mols }}{\int_{0}^{45 k m} \int_{0}^{t_{a c c}} G(z, t) d t d z}\right) \cdot 45 \mathrm{~km} .
$$

For visualization purposes, we consider the radii of cylinders stretching from the surface to the bottom of the crust which is equivalent to the volumes $V\left(t_{a c c}\right)$

$$
r\left(t_{a c c}\right)=\left(\frac{V\left(t_{a c c}\right)}{\pi \cdot 45 \mathrm{~km}}\right)^{1 / 2} .
$$

These equivalent crustal radii, $r\left(t_{a c c}\right)$, are plotted in Figure 9.

To estimate the crustal volumes required to produce the radiogenic noble gas abundances preserved in Bravo Dome, we require estimates of the accumulation ages of ${ }^{4} \mathrm{He}^{*}$ and ${ }^{40} \mathrm{Ar} *$. U-Pb geochronology and ${ }^{40} \mathrm{Ar} /{ }^{39} \mathrm{Ar}$ thermochronology show that the crust in this region has been retentive of ${ }^{40} \mathrm{Ar}^{*}$ for between $1.34 \mathrm{Ga}$ and $1.4 \mathrm{Ga}[42,43]$. Detrital zircon (U-Th)/He ages from the Tubb sandstone reflect sourcing from the Ancestral Rocky 
Mountain orogeny, implying that the crust proximal to Bravo Dome has been retentive of ${ }^{4} \mathrm{He}^{*}$ since $280-310 \mathrm{Ma}[44,45,21,22]$.

Using ${ }^{4} \mathrm{He}^{*}$ and ${ }^{40} \mathrm{Ar}^{*}$ bulk crustal ages and the calculated radiogenic parent concentrations, we calculate the crustal volumes needed to provide the observed amount of radiogenic gas in Bravo Dome. Assuming a closed system of radiogenic gases throughout the $45 \mathrm{~km}$ thick crust, a cylinder with a radius between $450 \mathrm{~m}$ and $510 \mathrm{~m}$ is required to produce the observed amount of ${ }^{4} \mathrm{He}^{*}$. Similarly, the ${ }^{40} \mathrm{Ar}^{*}$ catchment radius is between $300 \mathrm{~m}$ and $400 \mathrm{~m}$ (Figure 9). The small scale of these radii relative to the overall gas reservoir suggest that the gases migrated through a narrow fracture network in the crystalline basement. Furthermore, the different catchment volumes for ${ }^{4} \mathrm{He}^{*}$ and ${ }^{40} \mathrm{Ar}^{*}$ imply that ${ }^{4} \mathrm{He}^{*}$ and ${ }^{40} \mathrm{Ar}^{*}$ were fractionated from each other during the Ancestral Rocky Mountain tectonic event. Preferential removal of ${ }^{4} \mathrm{He}^{*}$ from the basement relative to ${ }^{40} \mathrm{Ar}^{*}$ is consistent with the higher diffusivity of ${ }^{4} \mathrm{He}^{*}$ in crustal minerals [40]. Furthermore, a larger fraction of ${ }^{4} \mathrm{He}^{*}$ resides in grain boundaries of the crust where it is susceptible to transport by fluid advection [33].

\subsection{Diffusion of Dissolved Gas through Evaporite Seal}

A competing hypothesis to explain the low ${ }^{4} \mathrm{He} /{ }^{40} \mathrm{Ar}$ ratio observed at Bravo Dome is diffusive loss of ${ }^{4} \mathrm{He}$ through the anhydrite reservoir seal. In order to estimate the maximum flux of ${ }^{4} \mathrm{He}$ through the $10 \mathrm{~m}$ thick evaporite seal overlying the Tubb Sandstone reservoir rock, we assume that the anhydrite contains $1 \%$ connected, water filled porosity. The gas in Bravo Dome, and across the US mid-continent region tends to be severely underpressured due to tight evaporite seals $[21,46]$, suggesting that the true effec- 


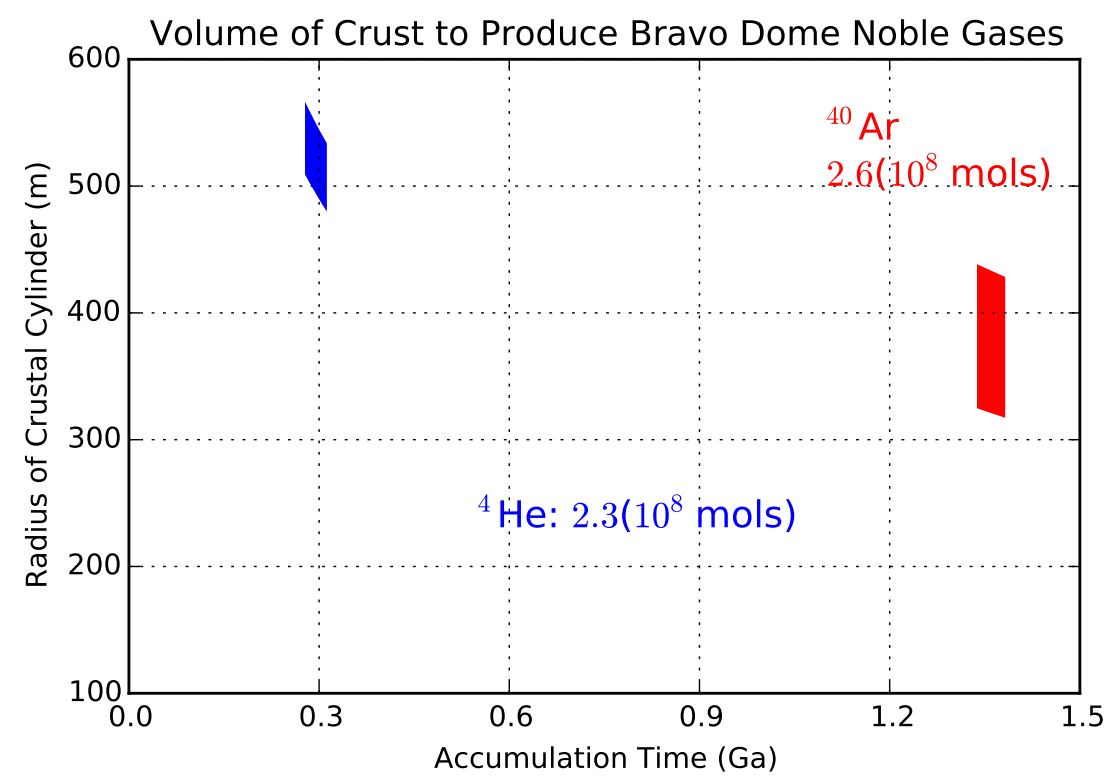

Figure 9: Crustal ${ }^{4} \mathrm{He}$ and ${ }^{40} \mathrm{Ar}$ production volumes. Estimates for accumulation ages correspond to regional ${ }^{40} \mathrm{Ar} /{ }^{39} \mathrm{Ar}(1.3 \mathrm{Ga}-1.4 \mathrm{Ga}$, dark red) and Zircon (U-Th)/He ages (280 Ma-310 Ma, dark blue). Using these ages, we estimate that the Bravo Dome gas entry event mobilized radiogenic ${ }^{4} \mathrm{He}$ from a volume of $43 \mathrm{~km}^{3}$, equivalent to a cylinder of 45 $\mathrm{km}$ thick crust with a $550 \mathrm{~m}$ radius. The range of possible values shown here corresponds to the black area in Figure 7. 
tive connected porosity approaches zero in these deposits. The diffusive flux of dissolved ${ }^{4} \mathrm{He}$ is

$$
J=-\frac{D \phi}{\tau} \frac{d C}{d z} .
$$

Assuming 1\% porosity throughout the seal, $100 \mathrm{ppm}{ }^{4} \mathrm{He}$ concentration, and a diffusivity, $D$, of $3.1 \cdot 10^{-9} \mathrm{~m}^{2} / \mathrm{s}$, the ${ }^{4} \mathrm{He}$ flux is $2 \cdot 10^{-7} \mathrm{~mol} /\left(\mathrm{m}^{2} \mathrm{yr}\right)$. Integrated over the reservoir age of $1.2 \mathrm{Ma}$ and area of $3.6 \cdot 10^{9} \mathrm{~m}^{2}$, the total mols of ${ }^{4} \mathrm{He}$ lost is $8.64 \cdot 10^{8}$ mols, greater than the total amount of ${ }^{4} \mathrm{He}$ in the reservoir. Argon is more soluble and less diffusive than helium, with a diffusivity of $1.65 \cdot 10^{-9} \mathrm{~m}^{2} / \mathrm{s}$ at the reservoir temperature, $30^{\circ} \mathrm{C}[39,20]$. These effects cause the flux of helium through a porous caprock to be only 1.3 times higher than the flux of argon.

Similarly, the diffusivity of $\mathrm{CO}_{2}$ at $40^{\circ} \mathrm{C}$ is half that of ${ }^{4} \mathrm{He}$, but $\mathrm{CO}_{2}$ is roughly 1000 times more soluble in water. The large solubility of $\mathrm{CO}_{2}$ leads to a 500 times greater diffusive flux for $\mathrm{CO}_{2}$ through trapping formations $[47,48,38]$. Because of this solubility effect, natural $\mathrm{CO}_{2}$ reservoirs require nearly impervious seals to prevent loss of $\mathrm{CO}_{2}$ through aqueous diffusion. Similar impervious evaporites have served as effective traps over geologic time for large commercial helium and $\mathrm{CO}_{2}$ reservoirs [49, 50, 20,30].

\section{Conclusion}

The noble gas volumes observed in the Bravo Dome natural $\mathrm{CO}_{2}$ reservoir and crustal scale diffusion models demonstrate that crystalline continental crust retains noble gases. The flux of ${ }^{4} \mathrm{He}^{*}$ and ${ }^{40} \mathrm{Ar}^{*}$ from the continental interiors to the atmosphere is sporadic and localized. At Bravo Dome, the abnormally low ${ }^{4} \mathrm{He}^{*} /{ }^{40} \mathrm{Ar}^{*}$ ratio is best explained by preferential fraction- 
ation by regional tectonic history. The radiogenic gas volumes show that a large scale fluid migration event such as the Bravo Dome $\mathrm{CO}_{2}$ entry was only able to mobilize $0.02 \%$ of underlying crustal noble gases. Accordingly, ${ }^{4} \mathrm{He}$ and ${ }^{40} \mathrm{Ar}$ mass-balance constraints on mantle structure and atmospheric formation should consider the potential correlation between degassing and the global supercontinent cycle.

\section{Acknowledgments}

We would like to thank Dr. Weisen Shen for providing seismic density profiles, Alexander Nereson for providing surface volcanics maps, and Kristopher Darnell for useful edits. KJS was funded by the UT Austin Statoil Doctoral fellowship. M. H. was supported by NSF Grant No. EAR-1215853.

\section{References}

[1] K. Turekian, The terrestrial economy of helium and argon, Geochimica et Cosmochimica Acta 17 (1959) 37-43.

[2] C. J. Allègre, A. Hofmann, K. O'Nions, The argon constraints on mantle structure, Geophysical Research Letters 23 (1996) 3555-3557.

[3] N. Coltice, F. Albarède, P. Gillet, ${ }^{40} \mathrm{~K}-{ }^{40} \mathrm{Ar}$ constraints on recycling continental crust into the mantle, Science 288 (2000) 845-847.

[4] T. Torgersen, Terrestrial helium degassing fluxes and the atmospheric helium budget: Implications with respect to the degassing processes of continental crust, Chemical Geology: Isotope Geoscience section 79 (1989) 1-14. 
[5] M. L. Bender, B. Barnett, G. Dreyfus, J. Jouzel, D. Porcelli, The contemporary degassing rate of ${ }^{40} \mathrm{Ar}$ from the solid earth, Proceedings of the National Academy of Sciences 105 (2008) 8232-8237.

[6] T. Torgersen, Continental degassing flux of ${ }^{4} \mathrm{He}$ and its variability, Geochemistry, Geophysics, Geosystems 11 (2010).

[7] I. M. Artemieva, W. D. Mooney, Thermal thickness and evolution of precambrian lithosphere: a global study, Journal of Geophysical Research: Solid Earth (1978-2012) 106 (2001) 16387-16414.

[8] D. D. Blackwell, M. C. Richards, Z. S. Frone, J. F. Batir, M. A. Williams, A. A. Ruzo, R. K. Dingwall, SMU Geothermal Laboratory Heat Flow Map of the Conterminous United States, 2011.

[9] R. L. , D. M. Fountain, Nature and composition of the continental crust: a lower crustal perspective, Reviews of Geophysics 33 (1995) 267-309.

[10] T. Torgersen, M. Stute, Helium (and other noble gases) as a tool for understanding long time-scale groundwater transport, Isotope methods for dating old groundwater, IAEA, Vienna (2013) 179-216.

[11] T. Torgersen, W. Clarke, Helium accumulation in groundwater, I: An evaluation of sources and the continental flux of crustal ${ }^{4} \mathrm{He}$ in the Great Artesian Basin, Australia, Geochimica et Cosmochimica Acta 49 (1985) $1211-1218$.

[12] M. Stute, C. Sonntag, J. Déak, P. Schlosser, Helium in deep circulating groundwater in the great hungarian plain: Flow dynamics and crustal 
and mantle helium fluxes, Geochimica et Cosmochimica Acta 56 (1992) 2051-2067.

[13] B. Marty, T. Torgersen, V. Meynier, R. K. O’Nions, G. Marsily, Helium isotope fluxes and groundwater ages in the Dogger Aquifer, Paris Basin, Water Resources Research 29 (1993) 1025-1035.

[14] M. C. Castro, M. Stute, P. Schlosser, Comparison of ${ }^{4} \mathrm{He}$ ages and ${ }^{14} \mathrm{C}$ ages in simple aquifer systems: implications for groundwater flow and chronologies, Applied Geochemistry 15 (2000) 1137-1167.

[15] Z. Top, W. Clarke, Dissolved helium isotopes and tritium in lakes; further results for uranium prospecting in central labrador, Economic Geology 76 (1981) 2018-2031.

[16] Z. Zhou, C. J. Ballentine, ${ }^{4}$ He dating of groundwater associated with hydrocarbon reservoirs, Chemical Geology 226 (2006) 309-327.

[17] R. Kipfer, W. Aeschbach-Hertig, F. Peeters, M. Stute, Noble gases in lakes and ground waters, Reviews in mineralogy and geochemistry 47 (2002) 615-700.

[18] N. Kampman, N. M. Burnside, Z. K. Shipton, H. J. Chapman, J. A. Nicholl, R. M. Ellam, M. J. Bickle, Pulses of carbon dioxide emissions from intracrustal faults following climatic warming, Nature Geoscience 5 (2012) 352-358.

[19] J. Lowenstern, W. Evans, D. Bergfeld, A. Hunt, Prodigious degassing of a billion years of accumulated radiogenic helium at Yellowstone, Nature 506 (2014) 355-358. 
[20] R. Broadhead, Bravo dome carbon dioxide gas field, in: E. Beaumont, N. Foster (Eds.), Structural Traps I: Tectonic Fold Traps, American Association of Petroleum Geologists, 1990.

[21] K. J. Sathaye, M. A. Hesse, M. Cassidy, D. F. Stockli, Constraints on the magnitude and rate of $\mathrm{CO}_{2}$ dissolution at bravo dome natural gas field, Proceedings of the National Academy of Sciences 111 (2014) $15332-15337$.

[22] C. F. Kluth, P. J. Coney, Plate tectonics of the Ancestral Rocky Mountains, Geology 9 (1981) 10-15.

[23] R. Wolf, K. Farley, L. Silver, Helium diffusion and low-temperature thermochronometry of apatite, Geochimica et Cosmochimica Acta 60 (1996) 4231-4240.

[24] M. A. Barnes, E. Y. Anthony, I. Williams, G. B. Asquith, Architecture of a 1.38-1.34 Ga granite-rhyolite complex as revealed by geochronology and isotopic and elemental geochemistry of subsurface samples from west Texas, USA, Precambrian Research 119 (2002) 9-43.

[25] A. W. Hofmann, Chemical differentiation of the earth: the relationship between mantle, continental crust, and oceanic crust, Earth and Planetary Science Letters 90 (1988) 297-314.

[26] B. R. Hacker, P. B. Kelemen, M. D. Behn, Continental lower crust, Annual Review of Earth and Planetary Sciences (2015).

[27] J.-C. Mareschal, C. Jaupart, Radiogenic heat production, thermal 
regime and evolution of continental crust, Tectonophysics 609 (2013) $524-534$.

[28] Geologic Map of New Mexico, Scale 1:500,000, New Mexico Bureau of Mines \& Mineral Resources, 2003.

[29] M. Cassidy, Occurrence and origin of free carbon dioxide gas deposits in the Earths crust, Ph.D. thesis, University of Houston, 2005.

[30] S. Gilfillan, C. J. Ballentine, G. Holland, D. Blagburn, B. S. Lollar, S. Stevens, M. Schoell, M. Cassidy, The noble gas geochemistry of natural $\mathrm{CO}_{2}$ gas reservoirs from the Colorado Plateau and Rocky Mountain provinces, USA, Geochimica et Cosmochimica Acta 72 (2008) 11741198.

[31] K. Farley, R. Wolf, L. Silver, The effects of long alpha-stopping distances on (U- Th)/He ages, Geochimica et Cosmochimica Acta 60 (1996) 42234229 .

[32] I. McDougall, T. M. Harrison, Geochronology and Thermochronology by the ${ }^{40} \mathrm{Ar} /{ }^{39} \mathrm{Ar}$ Method, Oxford University Press, 1999.

[33] C. J. Ballentine, P. G. Burnard, Production, release and transport of noble gases in the continental crust, Reviews in mineralogy and geochemistry 47 (2002) 481-538.

[34] W. Shen, M. H. Ritzwoller, V. Schulte-Pelkum, A 3-D model of the crust and uppermost mantle beneath the central and western US by joint inversion of receiver functions and surface wave dispersion, Journal of Geophysical Research: Solid Earth 118 (2013) 262-276. 
[35] R. Daly, G. E. Manger, S. P. Clark, Section 4: Density of rocks, Geological Society of America Memoirs 97 (1966) 19-26.

[36] S. Dye, Geoneutrinos and the radioactive power of the earth, Reviews of Geophysics 50 (2012).

[37] C. Clauser, E. Huenges, Thermal conductivity of rocks and minerals, Rock physics \& phase relations: A handbook of physical constants (1995) 105-126.

[38] R. Ferrell, D. Himmelblau, Diffusion coefficients of hydrogen and helium in water, AIChE Journal 13 (1967) 702-708.

[39] B. Jähne, G. Heinz, W. Dietrich, Measurement of the diffusion coefficients of sparingly soluble gases in water, Journal of Geophysical Research: Oceans (1978-2012) 92 (1987) 10767-10776.

[40] J. Braun, P. Van Der Beek, G. Batt, Quantitative thermochronology: numerical methods for the interpretation of thermochronological data, Cambridge University Press, 2006.

[41] W. Bach, D. Naumann, J. Erzinger, A helium, argon, and nitrogen record of the upper continental crust (KTB drill holes, Oberpfalz, Germany): Implications for crustal degassing, Chemical Geology 160 (1999) 81-101.

[42] Y. Li, M. A. Barnes, C. G. , C. D. Frost, Grenville-age A-type and related magmatism in southern Laurentia, Texas and New Mexico, USA, Lithos 97 (2007) 58-87. 
[43] R. E. Sanders, M. T. Heizler, L. B. Goodwin, ${ }^{40} \mathrm{Ar} /{ }^{39} \mathrm{Ar}$ thermochronology constraints on the timing of proterozoic basement exhumation and fault ancestry, southern Sangre de Cristo range, New Mexico, Geological Society of America Bulletin 118 (2006) 1489-1506.

[44] K. A. Hartig, G. S. Soreghan, R. H. Goldstein, M. H. Engel, Dolomite in permian paleosols of the bravo dome $\mathrm{CO}_{2}$ field, USA: Permian reflux followed by late recrystallization at elevated temperature, Journal of Sedimentary Research 81 (2011) 248-265.

[45] C. J. Ballentine, M. Schoell, D. Coleman, B. A. Cain, 300-Myr-old magmatic $\mathrm{CO}_{2}$ in natural gas reservoirs of the West Texas Permian Basin, Nature 409 (2001) 327-331.

[46] R. P. Sorenson, A dynamic model for the Permian Panhandle and Hugoton fields, western Anadarko basin, AAPG Bulletin 89 (2005) 921-938.

[47] P. J. Linstrom, W. Mallard, NIST Chemistry webbook; NIST standard reference database No. 69, 2001.

[48] W. Lu, H. Guo, I. Chou, R. Burruss, L. Li, Determination of diffusion coefficients of carbon dioxide in water between 268 and $473^{\circ} \mathrm{K}$ in a high-pressure capillary optical cell with in situ Raman spectroscopic measurements, Geochimica et Cosmochimica Acta 115 (2013) 183-204.

[49] T. P. Becker, R. Lynds, A geologic deconstruction of one of the world's largest natural accumulations of $\mathrm{CO}_{2}$, Moxa arch, southwestern Wyoming, AAPG Bulletin 96 (2012) 1643-1664. 
576 [50] C. J. Ballentine, B. Sherwood Lollar, Regional groundwater focusing 577 of nitrogen and noble gases into the Hugoton-Panhandle giant gas field, 578 USA, Geochimica et Cosmochimica Acta 66 (2002) 2483-2497. 